\title{
BMJ Open Association between antenatal care visit and preterm birth: a cohort study in rural Bangladesh
}

\author{
Jesmin Pervin, ${ }^{1}$ Syed Moshfiqur Rahman, ${ }^{2}$ Monjur Rahman, ${ }^{1}$ Shaki Aktar, ${ }^{1}$ \\ Anisur Rahman (D) ${ }^{1}$
}

To cite: Pervin J, Rahman SM, Rahman M, et al. Association between antenatal care visit and preterm birth: a cohort study in rural Bangladesh. BMJ Open 2020;10:e036699. doi:10.1136/ bmjopen-2019-036699

- Prepublication history and additional material for this paper are available online. To view these files, please visit the journal online (http://dx.doi org/10.1136/bmjopen-2019036699).

Received 30 December 2019 Revised 02 June 2020 Accepted 11 June 2020
Check for updates

(C) Author(s) (or their employer(s)) 2020. Re-use permitted under CC BY-NC. No commercial re-use. See rights and permissions. Published by BMJ.

${ }^{1}$ Maternal and Child Health Division, International Centre for Diarrhoeal Disease Research, Dhaka, Bangladesh

${ }^{2}$ International Maternal and Child Health, Department of Women's and Children's Health, Uppsala University, Uppsala, Sweden

Correspondence to

Dr Anisur Rahman;

arahman@icddrb.org

\section{ABSTRACT}

Background Strengthening the antenatal care programme is suggested as one of the public health strategies to reduce preterm birth burden at a population level. However, the evidence so far available is inconclusive.

Objectives To evaluate the association between antenatal care (ANC) visit and preterm birth; and also to explore to what extent the increased usage of ANC after the initiation of the Maternal, Neonatal and Child Health (MNCH) project in Matlab, Bangladesh, contributed to the reduction of preterm birth.

Setting This population-based cohort study was conducted in Matlab, a subdistrict under Chandpur. The analysis was based on data collected from 2005 to 2009. In 2007, an MNCH project was initiated in the area that strengthened the ongoing ANC services.

Participants In total, 12980 live births with their mothers during the study period were included in the analysis.

Analysis We performed logistic regression with generalised estimating equation models to evaluate the associations.

Outcome measures Preterm birth.

Results The number of ANC visits was associated with preterm birth in a dose-dependent way ( $p$ for linear trend $<0.001$ ). The adjusted odds of preterm birth were 2.4-times higher ( $0 \mathrm{R} 2.37,95 \% \mathrm{Cl} 2.07$ to 2.70 ) among women who received $\leq 1$ ANC compared with women who received $\geq 3$ ANC. We observed a significant reduction of preterm birth rates (OR $0.69,95 \% \mathrm{Cl} 0.61$ to 0.77 ) in the period after (2008 to 2009) MNCH project initiation in comparison to the period before (2005 to 2006). Controlling for ANC visits substantially attenuated this observed effect of the MNCH project on preterm birth (OR $0.88,95 \% \mathrm{Cl} 0.77$ to 0.99 ) (Sobel test of mediation $\mathrm{p}<0.001)$.

Conclusions ANC visits are associated with decreased occurrences of preterm births. Strengthening the ANC services should be prioritised in countries with high preterm birth rates to reduce the preterm birth burden at the population level.

\section{INTRODUCTION}

Preterm birth is one of the adverse pregnancy outcomes responsible for significant morbidity and mortality among children less than 5years of age. ${ }^{1}$ Out of the estimated

\section{Strengths and limitations of this study}

- To our knowledge, this is the first study in Bangladesh that evaluated the association between antenatal care (ANC) and preterm birth occurrence.

- The study includes population-based prospectively collected data with a low number of missing information.

- Lack of information on the uptake of individual intervention prevented understanding of the role of each service included in the ANC package in the study area.

- Residual confounding may remain after sociodemographic variables adjustment due to the differential of important behavioural characteristics between groups based on the number of ANC visits.

15 million babies born preterm every year worldwide approximately one million dies within 28 days of birth due to complications from being born too soon. ${ }^{2}{ }^{3}$ Prevention of preterm birth and its associated adverse health outcomes remain one of the major public health issues all over the world. The pregnancy period is considered a critical window of opportunity for shaping the future health and well-being of mothers, fetuses and neonates. ${ }^{4} 5$ Antenatal care (ANC) helps identify high-risk women to facilitate timely management of morbidities during pregnancy. ${ }^{5}$ It also influences the change of harmful practices associated with adverse maternal and newborn health outcomes, including preterm birth incidence. ${ }^{6-9}$ Strengthening the ANC programme is suggested as one of the public health strategies to reduce preterm birth burden at a population level. However, the evidence so far available is inconclusive.

Several studies have reported preterm birth associations with hypertensive disorder, vaginal bleeding and urogenital infections. ${ }^{10-13}$ Lifestyle factors such as physical activities, stress and smoking during pregnancy are also found to be related to preterm 
birth. ${ }^{14-17}$ An efficient ANC programme is expected to identify these maternal and social risk factors so that appropriate measures may be taken in time. Epidemiological studies have reported the associations between ANC uptake and preterm birth occurrence ${ }^{18-20}$ A populationbased study among adolescent pregnancies reported a strong association between inadequate ANC coverage and preterm birth. ${ }^{21}$ The risk increase in preterm birth is also correlated with the timing of care sought-the risk is higher in women who start ANC in late trimesters in comparison to women who started care in the early period of pregnancy. ${ }^{722} 23$

In contrast to the above findings, few studies did not observe any relationship between ANC uptake and preterm birth. ${ }^{2425}$ The evidence available so far is suggestive of an association between ANC and preterm birth occurrence. The earlier studies also had several limitations: the analyses mostly confined within a selected group of the population, the ANC package was not well described and the essential covariates were not available to adjust for potential confounding effects. Moreover, the number of studies from low-income countries is relatively low, with no report being available from Bangladesh thus far.

We initiated the Maternal, Neonatal and Child Health $(\mathrm{MNCH})$ project in 2007 in rural Matlab, Bangladesh, that implemented evidence-based maternal and child health interventions along the continuum of pregnancy through postpartum periods. The MNCH project demonstrated that the intervention caused up to $36 \%$ reduction in perinatal mortality over the 2 years period of the study. ${ }^{26} \mathrm{~A}$ substantial proportion of this mortality reduction was mediated by the increased usage of $\mathrm{ANC}^{27}$ Recently, we have demonstrated that the preterm birth rates decreased remarkably over the last 25 years in the same study area. About a quarter of this reduction was attributed to education and parity. ${ }^{28}$ However, the influence of the area's ANC services on preterm birth occurrence remained unexplored. In this paper, we evaluated the associations between ANC and preterm birth. We also explored the extent to which the increased usage of ANC after the initiation of the MNCH project contributed to the reduction of preterm birth in rural Matlab, Bangladesh.

\section{METHODS}

\section{Study setting, design and participants}

The study site is located in Matlab upazila under Chandpur district. The International Centre for Diarrhoeal Disease Research, Bangladesh (icddr,b) has been running a Health and Demographic Surveillance System (HDSS) over a population of about 220000 in the area since 1966. In half of the HDSS area, icddr,b provides healthcare services to the women of childbearing ages and their children less than 5 years in age. This service area is divided into four administrative blocks. Each block serves a population of about 27000 through a subcentre, staffed by midwives, that provides 24 hours delivery care. Clinical services in the subcentres are supported by an icddr,b Hospital, located in Matlab Municipality, that offers basic obstetric care and is staffed by medical doctors and nurses. In the study area, icddr,b provides all services including ANC free-of-cost. It also ensures the availability of healthcare providers, and all logistics and supplies to facilitate the uptake of recommended services to all clients.

In this paper, we first analysed the prospectively collected data from 2005 to 2009 to evaluate the association between the number of ANC visits and preterm birth occurrences. We then used a before-after study design within the cohort to assess the effect of ANC coverage on preterm birth occurrences between the periods before (2005 to 2006) and after (2008 to 2009) implementation of the MNCH project. In total, 12980 women who delivered live birth babies during the study period were included in the analysis.

The study participants in the MNCH Project provided the written informed consent.

\section{Antenatal care services in the study area}

According to the WHO's previous recommendation of four-visit focussed ANC for an uncomplicated pregnancy, we offer a minimum of four ANC services to all women in the icddr,b area. While the timing of ANC visits was flexible in the past, the schedule was fixed after the commencement of the $\mathrm{MNCH}$ project in 2007, with visits occurring 15 to 19, 24, 32 and 36 gestation weeks (GWs) of age. In the MNCH project period, we established an autogenerated ANC visit schedule based on the last menstrual period (LMP) dates of pregnant women to facilitate universal ANC coverage to all women in the study area. The ANC visit schedules were then sent to respective Community Health Workers (CHWs), subcentre clinics and icddr,b Hospital. The schedule was also recorded in the Take Action Card that contained educational materials to inform women of danger signs during pregnancy, delivery and postpartum periods. ${ }^{27}$ This ANC schedule recording helped women to recapitulate the date of their upcoming ANC visit from the respective icddr,b facility.

We offered a package of ANC services that covered activities such as history taking, physical examination, risk identification and management and counselling, including birth preparedness. During the MNCH project period, we continued all the services mentioned above. However, the project also strengthened some of the existing services (mostly the counselling and behaviour change communication) and added new interventions in the ANC package. The new interventions were: (i) routine ultrasound for assessment of fetal growth, multiple pregnancies, congenital anomalies and malpresentation, (ii) anti-helminthic supplementation in the second trimester, (iii) antibiotic use for women with preterm premature rupture of the membranes, (iv) corticosteroid use for women with the risk of preterm birth and (iv) routine assessment and treatment of urinary tract infections (UTIs) in women attending the icddr,b Hospital. We also standardised the 
existing counselling on nutrition, recognition of danger signs and birth preparedness by training all healthcare providers and introducing a checklist (online supplementary document S1) with periodic refresher training. The counselling was provided to women along with their support persons-the family members selected by the CHWs who agreed to be present during ANC visits and delivery. The details of ANC contents in the study area are described elsewhere (online supplementary document S2) ${ }^{27}$ In the study area, women who visited icddr,b facilities for ANC received all the interventions included in the ANC package adopted for that particular period.

\section{Data collection}

The present paper used the prospectively collected data by the HDSS from 2005 to 2009 and also used the MNCH databases for additional information from the period of 2008 to 2009 (online supplementary document S3). In the study area, CHW identified pregnancy during routine home visits at every 2-month interval by urine pregnancy test of a woman who had missed her LMP, CHW then recorded the reported dates if the pregnancy was confirmed. Subsequently, identified women were then followed up prospectively to capture information on pregnancy outcome and ANC usage. Exposure was assessed by the number of ANC women received.

Miscarriage was defined as the loss of a fetus before 28 weeks of gestation. Stillbirth was defined as the birth of a dead fetus at or above 28 weeks of gestation. Live birth was defined as delivery of a fetus with any sign of viability. ${ }^{26}$ Due to the unavailability of ultrasound assessment of gestation age during 2005 to 2006, we used reported LMP from the HDSS databases for the uniform assessment of gestational age during the study period. Gestational age was calculated by subtracting the LMP date from the date of delivery and was expressed in weeks. The outcome was preterm birth, which was defined as the delivery of a liveborn baby before 37 completed GWs of age.

Detailed information on covariates such as women's age, parity, socioeconomic condition, education, mode of delivery, year of delivery, inter-pregnancy intervals, previous preterm birth and previous adverse pregnancy outcomes was extracted from the HDSS databases. Parity was defined as the number of live or dead children before the current pregnancy. The education level was determined by the number of years attended in schools. We assessed the socioeconomic condition by generating scores through principal component analysis based on the ownership of household assets such as selected consumer items (television, watch, and so on), dwelling characteristics (wall and roof materials) and type of drinking water and toilet facilities. The generated scores were then categorised into quintiles, where 1 represented the poorest and 5 the richest. The mode of delivery was assigned as a vaginal or caesarean section delivery. We calculated the inter-pregnancy interval by subtracting the LMP date of index pregnancy from the previous pregnancy outcome date and expressed in months. In addition, we also calculated the gestational age of previous pregnancy, and categorised the live birth as previous preterm or term birth. Stillbirths or spontaneous abortions in the last pregnancy were considered as previous adverse pregnancy outcomes.

Due to data unavailability in the period before the $\mathrm{MNCH}$ project, we extracted some additional information from the MNCH databases to use in the analysis. We categorised ANC visits as timely or untimely for each visit window as per the protocol. ${ }^{26}$ The visit was considered timely if the women had received ANC in the period 15 to 19 GWs, 23 to 25 GWs and 31 to 33 GWs for first, second and third ANC visits periods, respectively. Visits outside the range were considered untimely. Body mass index (BMI) was calculated by weight in kilograms divided by the square of the height in metres $\left(\mathrm{kg} / \mathrm{m}^{2}\right)$. We diagnosed UTI if a woman had any symptoms (dysuria, frequency, urgency, lower abdominal or back pain and fever) of suspected UTI and if microscopic examination of urine revealed more than five pus cells per high power field. We also extracted the information if a woman was referred to a higher centre (from subcentre to icddr,b Hospital, or from icddr,b Hospital to subdistrict or district level facilities) for complications identified during ANC contact.

\section{Statistical analysis}

We analysed the data using descriptive and analytical approaches. In the analyses, live birth was categorised into preterm $(\mathrm{GWs}<37)$ and term $(\mathrm{GWs} \geq 37)$ births. Preterm birth was further categorised into very preterm ( $<32 \mathrm{GWs}$ ), moderate preterm (32 to $33 \mathrm{GWs)}$ and late preterm births (34 to $36 \mathrm{GWs}$ ). We categorised the ANC visits into $\leq 1,2$ and $\geq 3$ ANC visits due to a small number of women in 0 and $>3 \mathrm{ANC}$ visit groups. This categorisation of ANC visits is consistent with a previous publication with the same data set, ${ }^{27}$ and also facilitated comparison of the period before and after the MNCH project due to small number of sample with $>3$ visits in the earlier period. Further, the timeliness of ANC usage was categorised into timely or untimely. Among the available covariates, we categorised age into $<20,20$ to 24,25 to 34 or $\geq 35$ years, parity into 0,1 to 2 or $\geq 3$, education into 0,1 to 5 or $\geq 6$ years, and socioeconomic status by quintiles of asset scores. The number of birth was assigned as a singleton or twin birth. The inter-pregnancy interval was categorised into $<6,6$ to 11,12 to 17,18 to 23,24 to 47 and $\geq 48 \mathrm{~m}$ groups. Associations of covariates with ANC and preterm birth were determined by $\chi^{2}$ tests. A covariate was assigned as a confounding factor if it was associated with both ANC and preterm birth. We performed the multiple logistic regression using generalised estimating equation models to estimate the odds of preterm birth adjusted for the confounding factors. This analytical model allowed us to adjust for multiple pregnancies in a single subject. We also assessed the effect of ANC usage on preterm birth odds after inclusion of stillbirths. Results of the regression were presented by ORs with their $95 \%$ CIs. 
Table 1 The coverage of antenatal care visits by year in Matlab, Bangladesh

\begin{tabular}{|c|c|c|c|c|c|}
\hline & \multicolumn{5}{|c|}{ No. of antenatal care visits } \\
\hline & 0 & 1 & 2 & 3 & 4 or more \\
\hline & n (\%) & n (\%) & n (\%) & n (\%) & $\mathrm{n}(\%)$ \\
\hline 2006 & 86 (3.3) & $323(12.4)$ & $1039(40.0)$ & 1036 (39.9) & $112(4.3)$ \\
\hline 2007 & 127 (4.9) & $276(10.7)$ & 1015 (39.5) & 792 (30.8) & 358 (13.9) \\
\hline
\end{tabular}

To determine how ANC visits accounted for observed changes in preterm birth rates during the $\mathrm{MNCH}$ project period, we assessed the change in magnitude and significance of the pre-post intervention dummy variable (before $=0$; after $=1$ ) when adjusting for covariates, and ANC visits consecutively in different models. We conducted a Sobel test to assess whether ANC visits significantly mediated the effect of the MNCH intervention on the preterm birth rate. ${ }^{29}$

\section{Patient and public involvement}

Community residents or study participants were not involved in the elaboration of the research questions and study designs. There are no plans to disseminate the results of the research to study participants.

\section{RESULTS}

Out of 15518 pregnancies recorded by the HDSS, 13170 resulted in live births, 312 resulted in stillbirths and 2018 in miscarriages. Out of the total live birth deliveries, 190 had missing information on the sociodemographic variables, leaving 12980 births (12675 singletons and 305 twin birth) for analysis in the present paper.

During the MNCH study period, ANC usage was increased (table 1). The proportion of women with three or more ANC visits increased from $40 \%$ in 2005 to $82 \%$ in 2009. The median gestation age at the first ANC visit was 17 weeks for all groups of women who received 1 or 2 or $\geq 3$ ANC. The median gestation age at the second ANC visit was also the same ( 27 weeks) for women who received 2 or $\geq 3$ ANC. The median gestation age of preterm birth babies of women who received $\leq 1,2$ and $\geq 3$ ANC was 35, 35 and 36 weeks, respectively. Among the total preterm births in the groups $\leq 1 \mathrm{ANC}$ and $2 \mathrm{ANC}$, about $4 \%$ took place before 27 weeks.

There was a decreasing pattern of very, moderate and late preterm births during the study period; however, the decrease in late preterm birth was pronounced. Overall the preterm birth rate decreased from about $16.5 \%$ in 2005 to $11 \%$ in 2009 (table 2). We did not observe any changes in preterm birth proportions among the neonates born by caesarean section during the study period (table 2).
Table 3 presents the background characteristics of study women by year. Although we observed significant associations of the year of births with women's age, parity, attendance in school and socioeconomic condition by asset quintiles, the changes over the study periods were small. However, the caesarean section rates increased from $7 \%$ in 2005 to $18 \%$ in 2009 (table 3).

All the available covariates except inter-pregnancy interval and previous adverse pregnancy outcomes were found associated with ANC and preterm birth (table 4). Therefore, those factors were considered as potential confounders for adjustment in the regression model. Preterm births were more common in the older and higher birth order groups than in the younger and lower birth order groups, respectively. Higher school attendance and socioeconomic group women experienced less preterm birth occurrences in comparison to other groups. Women with previous preterm birth had a high proportion of preterm birth compared with women with previous term birth (table 4).

Additional information during the period of the $\mathrm{MNCH}$ project is presented in online supplementary table S1. The proportions of timely and untimely visits for first ANC visits were $68 \%$ and $32 \%$, for second ANC visits were $25 \%$ and $75 \%$ and for third ANC visits were $69 \%$ and $31 \%$, respectively. About $18 \%$ of women were underweight, $72 \%$ were normal weight and $10 \%$ were overweight. Among the women who attended ANC visits, about $3 \%$ had UTI and $10 \%$ were referred to a higher centre for complications (online supplementary table S1). We did not observe any association of preterm birth with prenatal BMI, UTI and referral to higher centres (data not shown).

In the logistic regression analysis, preterm birth was associated with the number of ANC visits in a dosedependent way ( $p$ for linear trend <0.001). ORs of preterm birth were 2.37 (95\% CI 2.07 to 2.70) and 1.73 (95\% CI 1.54 to 1.94 ) for women who received $\leq 1$ and 2 ANC visits, respectively, in comparison to the women who received $\geq 3$ ANC visits (table 5).

When the analysis was stratified in different preterm birth categories, the ORs of very, moderate and late preterm births to the women who received $\leq 1$ ANC were 5.80 (95\% CI 4.20 to 8.07 ), 2.11 (95\% CI 1.53 to 2.90$)$ and 1.77 (95\% CI 1.52 
to 2.06), respectively, compared with the women with $\geq 3$ ANC. The corresponding ORs for women with 2 ANC were 3.04 (95\% CI 2.19 to 4.23 ), 2.26 (95\% CI 1.72 to 2.97 ) and 1.40 (95\% CI 1.22 to 1.59 ), respectively, compared with the women who received $\geq 3$ ANC visits.

Furthermore, we observed that the odds of preterm birth increased for women with untimely visits compared with the women with timely visits after adjusting the available covariates. However, when the numbers of ANC visit categories were introduced in the model, the associations were no more observed (online supplementary table S2). We observed similar preterm birth odds when stillbirths were included in the analysis (online supplementary table S3).

We observed a $30 \%$ decrease in preterm birth odds (OR $0.70,95 \%$ CI 0.63 to 0.78 ) in the base model (no factor was adjusted for) among the women delivered in the study area after the intervention period. Consecutive adjustment of covariates in model 2 (maternal age, parity, education in year and asset quintile) and model 3 (the mode of delivery, previous preterm birth and multiple births), we observed almost no change in effect estimates with $31 \%$ decrease in preterm birth odds (OR 0.69, 95\% CI 0.61 to 0.77 ). In the final model (model 4 ), when we added ANC visits for adjustment, we observed substantial attenuation of the odds during the MNCH intervention period (OR 0.88, 95\% CI 0.77 to 0.99) (table 6). A Sobel test indicated that the reduction of effect when adjusting for ANC visit was statistically significant $(p<0.001)$. This finding suggests increasing ANC coverage accounted for the significant portion of the reduction of odds of preterm birth due to the MNCH programme.

\section{DISCUSSION}

Preterm birth remains one of the important public health problems worldwide. In the present study, we observed that the number of ANC visits was associated with preterm birth in a dose-dependent way. The women who attended more ANC visits had fewer probabilities of having preterm births. For the first time, we have demonstrated that high usage of ANC service appears to mediate a large proportion of the observed $31 \%$ decreased odds of preterm birth burden after the initiation of the MNCH project which helped in strengthening ANC services in the area (online supplementary document S1 and S2). The reduction in preterm was the probable direct effect of increased usage of ANC rather than the sociodemographic or selected reproductive health factors included in the analyses. The study findings underscore that ANC services might play a substantial role in the reduction of preterm birth at population level.

There is a scarcity of studies evaluating the association between usage of ANC and preterm birth occurrence. The study finding is consistent with a few studies that reported that women with inadequate ANC care had a higher risk of preterm birth. ${ }^{18193031}$ However, these studies are mostly from high-income countries. Therefore the effect 
Table 3 Characteristics of pregnant women in the study in Matlab, Bangladesh

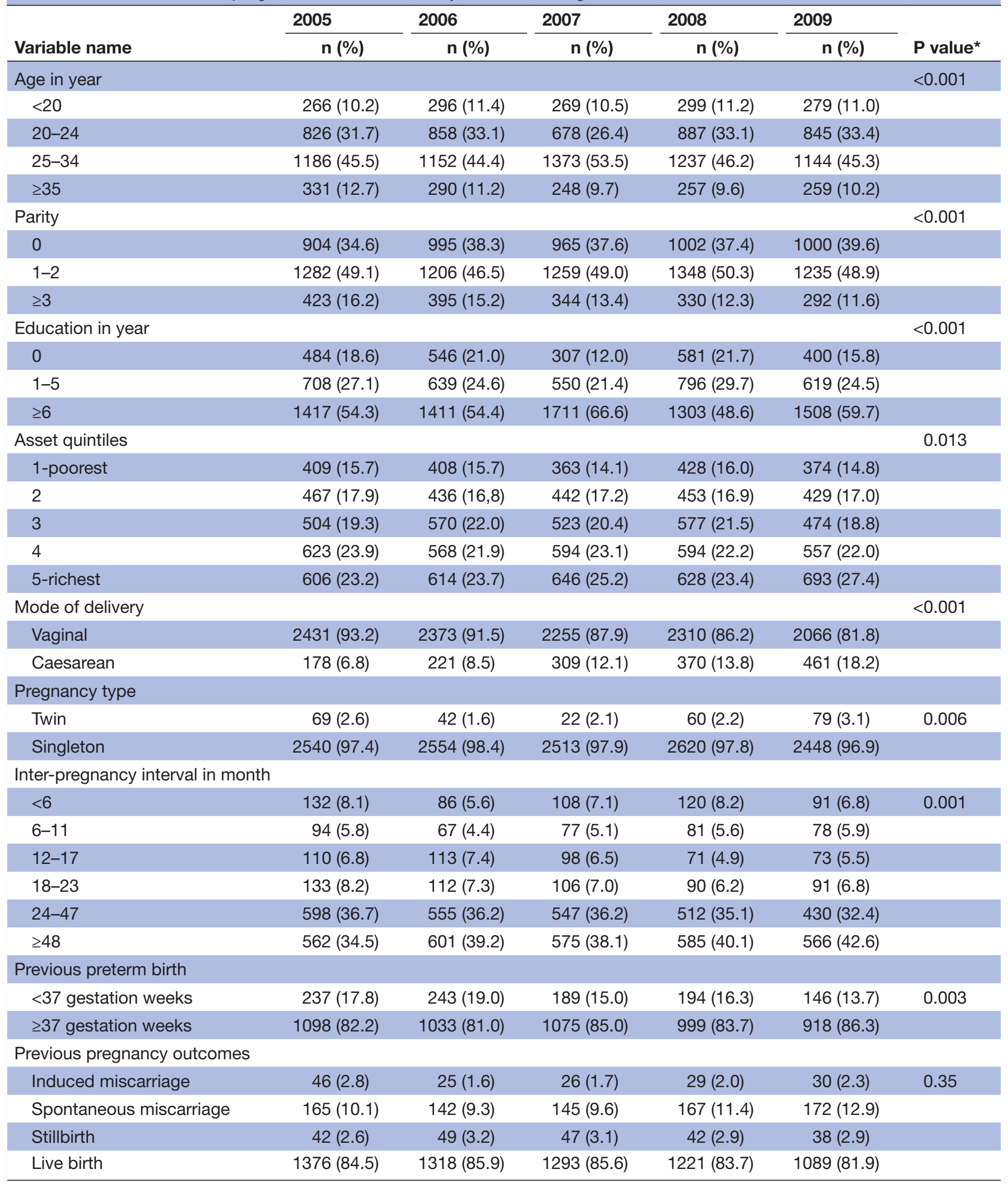

${ }^{*}$ By $\chi^{2}$ tests.

estimates may not be easily comparable due to differences in ANC contents and service delivery systems in low-income country settings. While two studies from USA and China and few systematic reviews showed a similar increased risk of preterm births with prenatal cares, they are not comparable to our findings due to dissimilarities 
Table 4 Association of background characteristics with antenatal care visits and gestational age at birth in Matlab, Bangladesh, 2005 to 2009

\begin{tabular}{|c|c|c|c|c|c|c|c|}
\hline & \multicolumn{4}{|c|}{ No. of antenatal care visits } & \multicolumn{3}{|c|}{ No. of births by gestational age } \\
\hline & \multirow{2}{*}{$\begin{array}{l}0-1 \\
n(\%) \\
\end{array}$} & \multirow{2}{*}{$\begin{array}{l}2 \\
n(\%) \\
\end{array}$} & \multirow{2}{*}{$\begin{array}{l}\geq 3 \\
\mathrm{n}(\%) \\
\end{array}$} & \multirow[b]{2}{*}{ P value* } & \multirow{2}{*}{$\begin{array}{l}<37 \text { weeks } \\
\mathrm{n}(\%)\end{array}$} & \multirow{2}{*}{$\begin{array}{l}\geq 37 \text { weeks } \\
\text { n (\%) }\end{array}$} & \multirow[b]{2}{*}{ P value* } \\
\hline & & & & & & & \\
\hline Age in year & & & & $<0.001$ & & & $<0.001$ \\
\hline$<20$ & $199(14.1)$ & 407 (28.9) & $803(57.0)$ & & $182(12.9)$ & $1227(87.1)$ & \\
\hline $20-24$ & $559(13.7)$ & $1141(27.9)$ & $2394(58.5)$ & & $524(12.8)$ & $3570(87.2)$ & \\
\hline $25-34$ & $894(14.7)$ & $1676(27.5)$ & $3522(57.8)$ & & $841(13.8)$ & $5251(86.2)$ & \\
\hline$\geq 35$ & $277(20.0)$ & $394(28.4)$ & $714(51.6)$ & & $320(23.1)$ & $1065(76.9)$ & \\
\hline Education in year & & & & $<0.001$ & & & $<0.001$ \\
\hline 0 & $435(18.8)$ & $659(28.4)$ & $1224(52.8)$ & & $424(18.3)$ & $1894(81.7)$ & \\
\hline $1-5$ & $508(15.3)$ & $912(27.5)$ & $1892(57.1)$ & & $550(16.6)$ & $2762(83.4)$ & \\
\hline$\geq 6$ & $986(13.4)$ & $2047(27.9)$ & $4317(58.7)$ & & $893(12.1)$ & $6457(87.9)$ & \\
\hline Parity & & & & $<0.001$ & & & $<0.001$ \\
\hline 0 & $610(12.5)$ & $1399(28.8)$ & $2857(58.7)$ & & $565(11.6)$ & $4301(88.4)$ & \\
\hline $1-2$ & $939(14.8)$ & $1707(27.0)$ & $3684(58.2)$ & & 909 (14.4) & $5421(85.6)$ & \\
\hline$\geq 3$ & $380(21.3)$ & $512(28.7)$ & $892(50.0)$ & & $393(22.0)$ & $1391(78.0)$ & \\
\hline Asset quintiles & & & & $<0.001$ & & & $<0.001$ \\
\hline 1-poorest & 365 (18.4) & $558(28.2)$ & $1059(53.4)$ & & 395 (19.9) & $1587(80.1)$ & \\
\hline 2 & $336(15.1)$ & $659(29.6)$ & $1232(55.3)$ & & $345(15.5)$ & $1882(84.5)$ & \\
\hline 3 & $435(16.4)$ & 754 (28.5) & $1459(55.1)$ & & $386(14.6)$ & $2262(85.4)$ & \\
\hline 4 & $382(13.0)$ & $798(27.2)$ & $1756(59.8)$ & & $375(12.8)$ & $2561(87.2)$ & \\
\hline 5-richest & $411(12.9)$ & $849(26.6)$ & $1927(60.5)$ & & $366(11.5)$ & $2821(88.5)$ & \\
\hline Mode of delivery & & & & $<0.001$ & & & 0.001 \\
\hline Vaginal & $1727(15.1)$ & $3257(28.5)$ & $6451(56.4)$ & & $1688(14.8)$ & $9747(85.2)$ & \\
\hline Caesarean section & $202(13.1)$ & 357 (23.2) & $980(63.7)$ & & $177(11.5)$ & $1362(88.5)$ & \\
\hline \multicolumn{8}{|c|}{$\begin{array}{l}\text { Inter-pregnancy interval in } \\
\text { month }\end{array}$} \\
\hline$<6$ & $92(17.1)$ & $154(28.7)$ & $291(54.2)$ & $<0.001$ & $93(17.3)$ & $444(82.7)$ & 0.096 \\
\hline $6-11$ & $69(17.4)$ & $96(24.2)$ & $232(58.4)$ & & 49 (12.3) & $348(87.7)$ & \\
\hline $12-17$ & $82(17.6)$ & $131(28.2)$ & $252(54.2)$ & & $81(17.4)$ & $384(82.6)$ & \\
\hline $18-23$ & $104(19.5)$ & $130(24.4)$ & $298(56.0)$ & & $84(15.8)$ & 448 (84.2) & \\
\hline $24-47$ & $425(16.1)$ & $708(26.8)$ & $1509(57.1)$ & & $383(14.5)$ & $2259(85.5)$ & \\
\hline$>=48$ & $369(12.8)$ & $819(28.3)$ & $1701(58.9)$ & & $473(16.4)$ & $2416(83.6)$ & \\
\hline \multicolumn{8}{|l|}{ Previous birth } \\
\hline$<37$ gestation weeks & 197 (19.5) & 297 (29.4) & $515(51.0)$ & $<0.001$ & $294(29.1)$ & 715 (70.9) & $<0.001$ \\
\hline$\geq 37$ gestation weeks & $741(14.5)$ & $1383(27.0)$ & $2999(58.5)$ & & $658(12.8)$ & $4465(87.2)$ & \\
\hline \multicolumn{8}{|c|}{$\begin{array}{l}\text { Previous adverse pregnancy } \\
\text { outcomes }\end{array}$} \\
\hline Yes & $133(13.2)$ & $264(26.2)$ & $612(60.7)$ & 0.047 & $148(14.7)$ & $861(85.3)$ & 0.789 \\
\hline No & $1008(15.6)$ & $1774(27.5)$ & 3671 (56.9) & & $1015(15.7)$ & $5438(84.3)$ & \\
\hline
\end{tabular}

${ }^{*}$ By $\chi^{2}$ tests.

in population, model selection or the way the prenatal care usage was measured. ${ }^{20} 2132$ On the other hand, a few studies did not find any association, and a discrepancy with our study findings may be due to the selected population group and different inclusion criteria in those studies. $^{2533}$

The possible role of ANC on the attenuation of the odds of preterm birth during the MNCH project period 
Table 5 Association between antenatal care and preterm birth among pregnant women in Matlab, Bangladesh, 2005 to 2009

\begin{tabular}{|c|c|c|c|c|}
\hline \multirow{2}{*}{$\begin{array}{l}\text { No. of } \\
\text { antenatal } \\
\text { care visit }\end{array}$} & \multicolumn{2}{|c|}{ Crude } & \multicolumn{2}{|c|}{ Adjusted* } \\
\hline & OR & $95 \%$ Cls & OR & $95 \%$ Cls \\
\hline$\leq 1$ & 2.63 & 2.32 to 2.99 & 2.37 & 2.07 to 2.70 \\
\hline 2 & 1.75 & 1.57 to 1.96 & 1.73 & 1.54 to 1.94 \\
\hline$\geq 3 \dagger$ & 1 & 1 & 1 & 1 \\
\hline
\end{tabular}

*Adjusted for women's age, parity, education in years, asset quintiles, mode of delivery, previous preterm birth and multiple births.

†Reference category

may not be fully explained; however, a few potential factors may be mentioned. Strengthening the existing prenatal care services and adding new interventions in the programme probably facilitated early detection and management of risk factors such as preterm birth in the previous pregnancy, multiple births, anaemia, diabetes, hypertensive disorders and UTIs, and thus influence preterm birth rate reduction (online supplementary document S1 and S2). The high usage of ANC services observed in our study signifies that the pregnant population was exposed to favourable preventive and curative services for preterm birth occurrence. Although inconclusive, the pronounced rate reduction in late preterm birth categories might be further construed as favouring the decline due to ANC. However, the lack of detail morbidity and nutrition information from the previous period of the MNCH project limited our ability to understand the causal pathway between the ANC service usage and preterm birth. Additionally, the possible causes of $12 \%$ decrease of preterm birth odds (OR $0.88,95 \%$ CI 0.77 to 0.99) during the MNCH intervention periods even after adjustment of ANC visits remain unexplained.

The strengths of our population-based study are the large sample size with information on dependent and independent variables collected prospectively, and also the inclusion of almost all pregnant population from a defined geographical area. Important sociodemographic and reproductive health factors were available to analyse and adjust for potential confounding effect. However, the study findings should be interpreted cautiously due to the inherent bias related to observation studies, as randomising the participants was not possible due to the universal acceptance of beneficial effect of ANC service provision on maternal and newborn health. Besides, the probability of ANC uptake directly depends on the duration of gestation before the occurrence of outcomes. However, the similar distributions of median gestation ages of preterm births and the significant difference of ORs between the women of $\leq 1$ ANC and 2 ANC usage groups, support the results of the present study. Exclusion of stillbirth from the analysis may lead to underestimation of preterm birth rates. ${ }^{34}$ However, it is commonly excluded from the calculation when reporting preterm birth and also for international comparison. ${ }^{34}$ Several studies in Bangladesh excluded stillbirths that reported the rates and risk factors of preterm births, ${ }^{35} 36$ including the one reported using the data from the same study area. $^{28}$ The observed similar effect estimates when stillbirths were included underscore that bias was unlikely due to measurement of preterm birth among live births only (online supplementary table S3).

Although the study has included several important covariates in the analyses, the observed results might be influenced by other unmeasured factors such as smoking, alcohol consumption and infections including, syphilis, HIV and malaria. However, the prevalence of these factors in pregnant women population in rural Bangladesh is extremely low, and therefore probably had no roles in the observed effect estimates. ${ }^{37-40}$ Other factors such as stress, physical activity, indoor air pollution and exposure to toxic metals that were reported to increase the risk of preterm births remain unmeasured in the study. ${ }^{41}$ Future studies should consider these factors to assess comprehensively the impact of ANC usage on preterm births.

The WHO recommended eight ANC contacts instead of four focussed ANC visits for an uncomplicated pregnancy in 2016. ${ }^{5}$ However, most of the low-income countries,

Table 6 Antenatal care and preterm birth before and after Maternal, Neonatal and Child Health (MNCH) project in icddr,b area Matlab, Bangladesh

\begin{tabular}{|c|c|c|c|c|}
\hline & \multicolumn{4}{|l|}{ ORs $\left(95 \%\right.$ Cls) ${ }^{*}$} \\
\hline & Model 1† & Model 2‡ & Model $3 \S$ & Model 4П \\
\hline \multicolumn{5}{|c|}{ Intervention period } \\
\hline After & 0.70 (0.63 to 0.78$)$ & 0.68 (0.60 to 0.76$)$ & 0.69 (0.61 to 0.77$)$ & 0.88 (0.77 to 0.99$)$ \\
\hline
\end{tabular}

*Consecutive adjustment of covariates in the model and changes of ORs on preterm birth before (2005 to 2006) and after (2008 to 2009).

†Base model-crude OR.

$\ddagger$ Adjusted for maternal age, parity, education and asset scores.

$\S$ Adjusted for covariates in the model $2+$ mode of delivery, previous preterm birth and multiple births.

ๆAdjusted for the covariates in model $3+$ number of antenatal care visits.

${ }^{* *}$ Reference category.

icddr,b, International Centre for Diarrhoeal Disease Research, Bangladesh. 
including Bangladesh, have not adopted the new recommendation yet. Further, the coverage of four ANC visits is still low in those countries. The recent report from Bangladesh Health and Demographic Survey in 2018 presented data for the last 3 years. It showed that the precentage of $3+$ ANC visits was about $58 \% .^{42}$ In the study area, we already achieved about $82 \% 3+$ ANC visits in 2009. In the present paper, we emphasise that the programme that achieves high ANC usage and ensures universal coverage of interventions in the ANC package (Document S2) for all clients may facilitate the reduction of preterm birth at the population level. Although the results emanated from $10+$ years old data, the finding is still relevant from public health points of view in Bangladesh and most of the lowincome countries.

In conclusion, we have reported the associations between ANC uptake and preterm birth incidence. Preterm birth remains one of the major causes of under 5 year mortality globally. ${ }^{1}$ Understanding the biology related to preterm birth incidence is still limited. To date, there is a lack of intervention that could reduce the preterm birth burden at a population level. An efficient ANC programme may address many of the socio-behavioural and reproductive factors linked to biological mediators such as infection, inflammation, stressors and nutritional factors causing preterm birth. ${ }^{43}$ Pending the availability of a new intervention to address the biological factors associated with preterm birth, the country with high preterm birth rates should prioritise strengthening the ANC services with increased coverage at a population level.

AcknowledgmentsWe thank the participants and their families in Matlab for their involvement in the MNCH study and the HDSS, Matlab; and also, the field team members for their excellent work. We gratefully acknowledge our core donors for their support and commitment to icddr,b's research efforts.

Contributions JP and AR contributed to the study concept and design. MR and AR supervised the data collection. JP, SMR, MR, SA and AR analysed the data. JP prepared the initial draft of the manuscript. All authors contributed to the preparation of the database, interpretation of the results and reviewed and approved the final version of the manuscript.

Funding This research study was funded by core donors who provide unrestricted support to icddr,b for its operation and research. Current donors providing unrestricted support include the Governments of Bangladesh, Canada, Sweden and the UK.

Disclaimer The funding agencies had no role in the design and conduct of the study, in the collection, analysis and interpretation of the data, or in the preparation, review or approval of the manuscript.

Competing interests None declared.

Patient consent for publication Not required.

Ethics approval The Ethical Review Committee of the International Centre for Diarrhoeal Disease Research, Bangladesh, approved the study (approved registration number 2006-040).

Provenance and peer review Not commissioned; externally peer reviewed.

Data availability statement Data are available upon reasonable request.

Open access This is an open access article distributed in accordance with the Creative Commons Attribution Non Commercial (CC BY-NC 4.0) license, which permits others to distribute, remix, adapt, build upon this work non-commercially, and license their derivative works on different terms, provided the original work is properly cited, appropriate credit is given, any changes made indicated, and the use is non-commercial. See: http://creativecommons.org/licenses/by-nc/4.0/.
ORCID iD

Anisur Rahman http://orcid.org/0000-0003-1033-5034

\section{REFERENCES}

1 Blencowe $\mathrm{H}$, Cousens S, Chou D, et al. Born too soon: the global epidemiology of 15 million preterm births. Reprod Health 2013;10(Suppl 1):S2.

2 Chawanpaiboon S, Vogel JP, Moller A-B, et al. Global, regional, and national estimates of levels of preterm birth in 2014: a systematic review and modelling analysis. Lancet Glob Health 2019;7:e37-46.

3 Lawn JE, Gravett MG, Nunes TM, et al. Global report on preterm birth and stillbirth (1 of 7): definitions, description of the burden and opportunities to improve data. BMC Pregnancy Childbirth 2010;10(Suppl 1):S1.

4 AbouZahr C. Safe motherhood: a brief history of the global movement 1947-2002. Br Med Bull 2003;67:13-25.

5 World Health Organization. WHO recommendations on antenatal care for a positive pregnancy experience, 2016.

6 Alexander GR, Kotelchuck M. Quantifying the adequacy of prenatal care: a comparison of indices. Public Health Rep 1996;111:408-18. discussion 19.

7 Asundep NN, Jolly PE, Carson A, et al. Antenatal care attendance, a surrogate for pregnancy outcome? The case of Kumasi, Ghana. Matern Child Health J 2014;18:1085-94.

8 Barros FC, Bhutta ZA, Batra M, et al. Global report on preterm birth and stillbirth (3 of 7): evidence for effectiveness of interventions. BMC Pregnancy Childbirth 2010;10(Suppl 1):S3.

9 Fernandez Turienzo C, Sandall J, Peacock JL. Models of antenatal care to reduce and prevent preterm birth: a systematic review and meta-analysis. BMJ Open 2016;6:e009044.

10 Ananth CV, Vintzileos AM. Medically indicated preterm birth: recognizing the importance of the problem. Clin Perinatol 2008;35:53-67. viii.

11 Bloom SL, Yost NP, Mclntire DD, et al. Recurrence of preterm birth in singleton and twin pregnancies. Obstet Gynecol 2001;98:379-85.

12 Goldenberg RL, Hauth JC, Andrews WW. Intrauterine infection and preterm delivery. N Engl J Med 2000;342:1500-7.

13 Hackney DN, Glantz JC. Vaginal bleeding in early pregnancy and preterm birth: systemic review and analysis of heterogeneity. $J$ Matern Fetal Neonatal Med 2011;24:778-86.

14 Hegaard HK, Pedersen BK, Nielsen BB, et al. Leisure time physical activity during pregnancy and impact on gestational diabetes mellitus, pre-eclampsia, preterm delivery and birth weight: a review. Acta Obstet Gynecol Scand 2007;86:1290-6.

15 Ion R, Bernal AL. Smoking and preterm birth. Reprod Sci 2015;22:918-26.

16 Lilliecreutz C, Larén J, Sydsjö G, et al. Effect of maternal stress during pregnancy on the risk for preterm birth. BMC Pregnancy Childbirth 2016;16:5.

17 Newnham JP, Dickinson JE, Hart RJ, et al. Strategies to prevent preterm birth. Front Immunol 2014;5:584.

18 Blondel B, Dutilh P, Delour M, et al. Poor antenatal care and pregnancy outcome. Eur J Obstet Gynecol Reprod Biol 1993;50:191-6.

19 Vintzileos AM, Ananth CV, Smulian JC, et al. The impact of prenatal care in the United States on preterm births in the presence and absence of antenatal high-risk conditions. Am J Obstet Gynecol 2002;187:1254-7.

20 Zhang B, Yang R, Liang S-W, et al. Association between prenatal care utilization and risk of preterm birth among Chinese women. $J$ Huazhong Univ Sci Technolog Med Sci 2017;37:605-11.

21 Debiec KE, Paul KJ, Mitchell CM, et al. Inadequate prenatal care and risk of preterm delivery among adolescents: a retrospective study over 10 years. Am J Obstet Gynecol 2010;203:122.e1-6.

22 Barros H, Tavares M, Rodrigues T. Role of prenatal care in preterm birth and low birthweight in Portugal. J Public Health Med 1996;18:321-8.

23 Beeckman K, Louckx F, Downe S, et al. The relationship between antenatal care and preterm birth: the importance of content of care. Eur J Public Health 2013;23:366-71.

24 Kramer MS. Determinants of low birth weight: methodological assessment and meta-analysis. Bull World Health Organ 1987;65:663-737.

25 McDuffie RS, Beck A, Bischoff K, et al. Effect of frequency of prenatal care visits on perinatal outcome among low-risk women. A randomized controlled trial. JAMA 1996;275:847-51.

26 Rahman A, Moran A, Pervin J, et al. Effectiveness of an integrated approach to reduce perinatal mortality: recent experiences from Matlab, Bangladesh. BMC Public Health 2011;11:914. 
27 Pervin J, Moran A, Rahman M, et al. Association of antenatal care with facility delivery and perinatal survival - a population-based study in Bangladesh. BMC Pregnancy Childbirth 2012;12:111.

28 Rahman A, Rahman M, Pervin J, et al. Time trends and sociodemographic determinants of preterm births in pregnancy cohorts in Matlab, Bangladesh, 1990-2014. BMJ Glob Health 2019;4:e001462.

29 Preacher KJ, Hayes AF. SPSS and SAS procedures for estimating indirect effects in simple mediation models. Behav Res Methods Instrum Comput 2004;36:717-31.

30 Blondel B, Marshall B. Poor antenatal care in 20 French districts: risk factors and pregnancy outcome. J Epidemiol Community Health 1998;52:501-6.

31 Taylor CR, Alexander GR, Hepworth JT. Clustering of U.S. women receiving no prenatal care: differences in pregnancy outcomes and implications for targeting interventions. Matern Child Health $\mathrm{J}$ 2005;9:125-33.

32 Hollowell J, Oakley L, Kurinczuk JJ, et al. The effectiveness of antenatal care programmes to reduce infant mortality and preterm birth in socially disadvantaged and vulnerable women in highincome countries: a systematic review. BMC Pregnancy Childbirth 2011;11:13.

33 White DE, Fraser-Lee NJ, Tough S, et al. The content of prenatal care and its relationship to preterm birth in Alberta, Canada. Health Care Women Int 2006;27:777-92.

34 Morisaki N, Ganchimeg T, Vogel JP, et al. Impact of stillbirths on international comparisons of preterm birth rates: a secondary analysis of the who multi-country survey of maternal and newborn health. BJOG 2017;124:1346-54.
35 Khanam R, Lee AC, Mitra DK, et al. Maternal short stature and under-weight status are independent risk factors for preterm birth and small for gestational age in rural Bangladesh. Eur J Clin Nutr 2019;73:733-42.

36 Shah R, Mullany LC, Darmstadt GL, et al. Incidence and risk factors of preterm birth in a rural Bangladeshi cohort. BMC Pediatr 2014;14:112.

37 (NASP) NASP, Services DGoH, Welfare MoHaF. 4Th national strategic plan for HIV and AIDS response 2016:2018-22.

38 Islam JY, Zaman MM, Bhuiyan MR, et al. Alcohol consumption among adults in Bangladesh: results from STEPS 2010. WHO South East Asia J Public Health 2017;6:67-74.

39 Islam N, Bonovas S, Nikolopoulos GK. An epidemiological overview of malaria in Bangladesh. Travel Med Infect Dis 2013;11:29-36.

40 Nargis N, Thompson ME, Fong GT, et al. Prevalence and patterns of tobacco use in Bangladesh from 2009 to 2012: evidence from international tobacco control (ITC) study. PLoS One 2015;10:e0141135

41 Behrman RE, Butler AS. Preterm birth: causes, consequences, and prevention. Washington, DC: The National Academies Press, 2006.

42 National Institute of Population Research and Training (NIPORT), and ICF. Bangladesh demographic and health survey 2017-18: key indicators. Dhaka, Bangladesh, and Rockville, Maryland, USA: NIPORT, and ICF, 2019.

43 Lackritz EM, Wilson CB, Guttmacher AE, et al. A solution pathway for preterm birth: accelerating a priority research agenda. Lancet Glob Health 2013;1:e328-30. 